\title{
LOS NOMBRES DE LA VIOLENCIA Y EL CONTROL DE SU LEGITIMACIÓN*
}

\author{
por \\ ISABEL ALFONSO \\ Instituto de Historia, CSIC
}

Recientemente, a raíz del sangriento conflicto de los balcanes, un conocido escritor reflexionaba en uno de los periódicos de más tirada del país, sobre el misterio insondable de la crueldad bumana, que le llevaba a decir que había que 'aceptar (la) bumildemente como algo natural, efecto de una descompensación de minerales en algún bulbo del cerebro', desconcertado menos por la violencia en si que por el espectáculo de su justificación a través de los calificativos de 'legítima defensa', 'guerra justa' o 'guerra bumanitaria' que trataban de imponer sus organizadores'.

Como estudiosos sociales sabemos de la fuerza del lenguaje en la imposición de un poder que se detenta o disputa. Como historiadores no deja de sorprendernos la permanencia a lo largo del tiempo de discursos de legitimación similares. Ciertamente, la cercanía de un conflicto como el señalado parece haber reavivado viejos interrogantes y discusiones acerca de la naturaleza biológica o cultural de la violencia, sobre la permanencia y multiplicidad de sus formas, sobre las causas que la originan y sobre los modos de erradicarla o limitarla...cuestiones todas ellas ligadas tradicionalmente, como es bien sabido, a temas de orden y pacificación social, de control y legitimidad, pero de forma creciente

* Las reflexiones contenidas en estas páginas forman parte de una investigación más amplia en el marco del Proyecto de Investigación sobre Lucha y legitimación política en León y Castilla (siglos $X-X V$ ) [PB98-0655]. Agradezco a Julio Escalona la lectura y útiles comentarios sobre este artículo.

1 VICENT, M.: «La crueldad», en El País, 11-IV- 1999. 
abordadas desde diferentes campos de estudio, en relación a los procesos sociales por los cuales percibimos, cualificamos y representamos la violencia como tal.

Sobre estos problemas versan los libros que voy a reseñar ${ }^{2}$, pues aunque la palabra violencia sólo forma parte del título de uno, es el tema central de todos ellos, siendo la diversidad de las fuentes utilizadas y de las perspectivas desde las que son tratadas uno de los mayores estímulos, también de las mayores dificultades, para elaborar estas notas, que no intentan, por ello, dar cuenta ajustada de su contenido sino señalar los marcos de discusión en los que se sitúan explícitamente los autores o que constituyen su referente implícito. La línea argumental pretende reflexionar sobre el papel del historiador, de su posición en una cadena, como observador de la violencia, perceptor e interprete de la información sobre la misma que encuentra en el material que maneja, artífice también de una narrativa con sus propias convenciones y retórica explicati$\mathrm{va}^{3}$. Porque los debates más importantes presentes en estos libros tienen que ver con nuestras propias percepciones, que se construyen o cambian, se ratifican o cuestionan también por la escritura histórica.

Mientras el libro de Thomas Bisson, parece escrito para ratificar, aunque de forma matizada, la vieja y arraigada imagen de la violenta anarquía ${ }^{4}$ feudal, erigiéndose en portavoz de sus víctimas en lo que denomina una historia compasiva (compassionate history), los otros dos, de carácter colectivo ambos, parecen, por el contrario, compartir el común objetivo, puesto de relieve por sus coordinadores, de cuestionar esa misma imagen historiográfica muy extendida de una edad media tan obscura como violenta en un intento serio de identificar las formas de esa violencia, explorar los contextos en que se produce y entender el papel que cumplen, recuperar, en fin, la lógica de funcionamiento de las sociedades estudiadas. El coordinado por Guy Halsall, constituido por once capítulos, debidos a otros tantos autores, aborda aspectos de la violencia en diferentes áreas de la Europa altomedieval. El que coordina Barbara Rosenwein lo componen diez artículos, también de autores diferentes, que exploran como

2 Halsall, Guy. (ed.): Violence and Sociey in the Early Medieval West. London, The Boydell Press, 1998, 230 págs.; RosenweIn, Barbara. (ed.): Anger's Past. The Social Uses of an Emotion in the Middle Ages, Ithaca and London, Cornell University Press, 1998, 256 págs.; Bisson, Thomas N.: Tourmented Voices. Power, Crisis, and Humanity in Rural Catalonia, 114-1200, Cambridge, Harvard University Press, 1998, 186 págs.

3 El papel del observador en esa triada de actores que intervienen en la valoración de la violencia ha sido brillantemente resaltado por MILLER, William I. en un libro fascinante, Humillation and Other essays on Honor, Social Discomfort, and Violence. Ithaca, 1993.

4 Cierto que Bisson no usa dicha expresión, como él mismo precisa en su respuesta a las criticas que suscitó su artículo sobre la revolución feudal (pág. 211), pero el concepto de 'anarquía' le parece bien documentado, según señala en n. 37 (pág. 221). 'The «Feudal Revolution»' en Past and Present, 142 (1994), págs. 6-42. Las intervenciones de S. White, D. Barthélemy, Ch. Wickham, T. Reuter, en la misma revista, $\mathrm{n}^{\circ}$ s. 152 (1996) y 155 (1997), donde se incluye la 'Reply' de Bisson. 
indica el subtítulo, el uso social de una de sus más emotivas manifestaciones. Ambos libros, en cierta medida, se complementan, pues mientras en el primero los temas de vocabulario político y legitimación social reciben mayor atención, en este otro se atiende más a los aspectos emocionales de las reacciones violentas, a su representación y percepción. El trabajo de Bisson centrado sobre los sesenta últimos años del siglo XII en los que en su opinión se produce en el campo catalán la crisis del orden político anterior sustituido por el 'desorden' y 'arbitraria violencia' señorial, participa de ambas temáticas.

La larga introducción de Halsall a Violence and Sociey (págs. 1-45), sin duda dirigida a dar coherencia al conjunto y a mostrar las preocupaciones que impulsaron su trabajo de editor, debería haberse incluido en la parte final como epílogo o conclusiones, pues más que presentar los trabajos, dialoga con ellos, relaciona los problemas que plantean e identifica y reflexiona sobre los principales debates. Su lectura, en mi opinión, resulta más útil entonces, mi discusión también lo será más adelante. Cabría reunir los artículos de este libro en torno a dos grandes ejes temáticos: violencia y orden sociopolítico, para los ocho primeros, y violencia de y contra las mujeres, para los tres últimos. Luis García Moreno ('Legitimate and illegitimate violence in Visigothic law', págs. 46-59) describe la violencia de lo que denomina proceso de proto-feudalización de la sociedad visigoda, a partir de su condena por la legislación regia; protagonizada por los poderosos, esta violencia - nos dice - amenazaba la estabilidad del estado de derecho que el reino godo pretendía ser. La valoración que hace este autor de la violencia aristocrática en dicha sociedad difiere de la que para su coetánea merovingia ofrece Paul Fouracre ('Attitudes towards violence in seventh and eight century Francia', págs. 60-75). Especialmente critico con las lecturas positivistas del material que utiliza el historiador, interesado menos en cuantificar la violencia que en entender cómo se construye socialmente, no niega que tal violencia existiese, al contrario la ve como un elemento de su organización política, dependiente en gran parte de la rivalidad entre diferentes facciones de nobles, capaces de ejercer la fuerza militarmente. Excepcional a gran escala, medio de redistribución del poder en la corte regia, con participación por tanto de los mismos reyes, esta violencia, en opinión de Fouracre, nunca comprometió la estabilidad social pues reforzaba más que debilitaba el poder y jerarquía social. La moralización de la política por una creciente cristianización del lenguaje no le impide observar el desarrollo de una actitud pragmática hacia dicha violencia, juzgada buena o mala según los casos. Así, los mayores niveles de violencia que parecen caracterizar la sociedad tardo merovingia se explican en gran parte, según este autor, por elaboraciones posteriores en el marco de la propia legitimación carolingia y por un cambio de orientación de las fuentes conservadas, de hagiografías centradas en conflictos internos, a historias que lo hacen sobre los externos. En esta misma línea, Janet Nelson («Violence in the Carolingian world and the ritualization of ninthcentury warfare», págs. 90-107) insiste en la importancia de la influencia ecle- 
siástica en los nuevos recursos ideológicos y litúrgicos que justificaban la violencia tanto hacia fuera como en el interior del imperio carolingio en defensa de la res publica cristiana. La denominación de los conflictos cambia: rivalidades y disputas privadas, señala, se convierten en 'guerra civil' cuando los carolingios se enfrentan entre ellos. La ritualización eclesiástica, como medio de legitimación de estas guerras facilitó igualmente la formación y aceptación de las nuevas estructuras políticas de los reinos medievales surgidos de la división del imperio. El proceso, en el que se hizo intervenir la voluntad divina, supuso también la validación de la violencia de las elites militares caballerescas. Su artículo, aborda así un tema esencial, el de la violencia estatal legitimada, institucionalizada como elemento necesario tanto para construirse como para reproducirse como tal poder, en una perspectiva que va más allá del reconocimiento legal de determinadas formas de violencia.

El problema de la relación entre violencia y creación de un orden sociopolítico nuevo, es tratado también por S. J. Speigh ( $V$ Violence and the creation of socio-political order in post-conquest Yorkshire», págs. 157-174), esta vez para el Yorkshire posterior a la conquista normanda, que fue especialmente violenta en esta zona, aunque la violencia, viene a decir, no fue diferente a la utilizada por los reyes ingleses y escoceses en sus intentos previos por controlarla. Señala acertadamente, que la forma en que se desarrolló la intervención tuvo que ver con el tipo de relaciones que pudieron, o no, establecerse con los distintos poderes locales, y que el modo en que los cronistas posteriores calificaron dicha violencia es parte del proceso de legitimación o condena del nuevo poder, en contraste con la valoración de las acciones de los que se opusieron a su establecimiento. Señala igualmente los problemas originados por la distribución de la tierra como inherentes a la dura competición por la misma practicada tanto por normandos como por sajones, y llama la atención sobre la intimidación psicológica y la humillación, como armas tan potentes como la violencia física, en el proceso de imposición del nuevo orden y de sometimiento de la población nativa. En cierta medida, aunque no se trate de un dominio importado, Guy Morris («Violence and late Viking Age Scandinavian social order», págs. 141-156) investiga un problema similar al ocuparse de la utilización de la violencia por los vikingos para afirmar el orden social y político en el interior de la sociedad escandinava. La violencia regia, justificada como casi por todas partes apelando a la traición de aquellos contra los que se dirige, parece concluir, tenía que ver con su construcción como poder superior sobre una aristocracia muy jerarquizada en el interior, y con la formación de fronteras territoriales frente a otros reinos.

De una forma específica de violencia política, de una modalidad de regicidio ritual, que parece dirigida a enmascarar la lucha por el poder en sucesiones intradinásticas o en el curso de guerras entre reinos, se ocupa el capítulo de Nick B. Aitchison sobre Irlanda ("Regicide in early medieval Ireland», págs.108-125). Los rituales en los que se da muerte a los reyes se presentan como actos propiciatorios por la salud del reino, que las víctimas habían puesto 
en peligro al no cumplir sus sagrados deberes regios. La funcionalidad legitimadora de estos rituales sigue vigente en el siglo IX por lo que, como el autor resalta, no cabe atribuirlos a formas tribales de la monarquía irlandesa.

Compartiendo la misma preocupación de cuestionar asunciones muy extendidas, de criticar lecturas positivistas de las fuentes, está el trabajo de Tom S. Brown («Urban violence in early medieval Italy: the cases of Rome and Ravenna», págs.76-89) sobre los conflictos en ciudades italianas altomedievales. Muestra, que la ciudad como ámbito pacificador, expresión de un orden civilizado, es un mito, o mejor, un elemento de la retórica del poder; que la existencia de luchas faccionales en ellas no es algo privativo del período bajomedieval, sino muy anterior. Señala el carácter legitimador de la lucha faccional que en las 'guerras de sucesión' papales en Roma, supusieron las invocaciones a la intervención popular. Respecto a Ravena, la lectura de las fuentes que ofrece muestra también una narrativa en la cual la violencia atribuida a los otros sirvió como elemento retórico para resaltar el papel unificador y pacificador del obispo. Cuestiona así la visión elaborada por los clérigos urbanos de una violencia integradora, de identidad comunitaria frente a la influencia bizantina. Este estudio implica una redefinición de la naturaleza que se ha atribuido a esas luchas, habría que decir a su ocultación anterior.

Pero es el artículo de Matthew Bennet («Violence in eleveth-century Normandy: feud, warfare and politics», págs. 126-140) el que de forma más explícita discute la naturaleza de la violencia en función de las denominaciones que reciben, antes y ahora, los conflictos. Centrado en los de la Normandía del siglo XI, niega que fueran 'guerras privadas' o 'venganzas de sangre's, y con ello el carácter anárquico que les atribuye toda una larga tradición historiográfica. En su opinión hay que verlos como expresiones de 'política' y 'warfare', no de 'feud', es decir como vías de resolución de conflictos por el poder entre los que competían políticamente por el mismo y tenían medios militares para proseguirlas. Considero que son de apreciar los intentos de este autor por distinguir e identificar diferentes conflictos, desentrañar sus causas y formas de resolverlos, pero su visión estricta de feud, resultado de aceptar la acepción moderna, como venganza personal, familiar, en casos de enemistad mortal me parece cuestionable. Los autores que cita (White, Barlett, Hyams, Miller) han ofrecido un panorama más complejo de la lucha por el poder y competición política que tales términos indican ${ }^{6}$. Y al contrario que él, es otorgando carácter político a

5 Los términos más usuales para el inglés feud.

6 WHITE, Stephen, 'Feuding and Peacemaking om the Touraine around the year 1100', en Traditio, 42, 1986, págs. 195-263'; BARLETT, Robert: 'Mortal enmities': the legal aspect of hostility. in the Middle Ages', en T Jones Pierce Lecture, 1998, págs. 1-18; HYAMs, Paul: 'Feud in Medieval England', en The Haskins Society Journal, 3, 1991, págs. 1-21. MILLER, William, I.: Bloodtaking and Peacemaking; Feud, Law an Society in Saga Iceland, Chicago, 1990.

Hispania, LXI/2, núm. 208 (2001) 691-706 
esos conflictos, como niegan la anarquía de la violencia que producen. Sin embargo, la propia distinción de Bennet entre conflictos 'políticos' y 'no políticos', indicativa de una noción muy estrecha del campo político, supone -piensoasumir la vieja dicotomía, que parece criticar entre 'público' y 'privado' (págs. 130-1) ${ }^{7}$. En última instancia, el problema se desplaza a la noción de política que se utilice, tan problemática como la de violencia, y el argumento se puede convertir en circular, si se queda en puro nominalismo. En el tipo de sociedad que describe en la que los grupos se representan y articulan por vínculos de parentesco, amistad y fidelidad, los conflictos han de estar más imbricados de lo que este autor hace aparecer. Más interesante sería, y algunos de los ejemplos que utiliza lo permiten (pág. 130), investigar cómo se mezclan, deliberadamente incluso, unos y otros conflictos, cómo cuestiones personales se logran expandir a ámbitos más generales ${ }^{8}$. Dos problemas importantes, por tanto, me parece plantea, que no resuelve, el trabajo de Bennet: de qué depende el carácter político que se otorga o niega a los conflictos estudiados y la relación entre estructuras políticas y formas de violencia. Volveremos sobre ellos más adelante, pues ocupan la mayor parte de la introducción del editor y subyacen también al resto de los artículos de éste y de los otros dos libros aquí comentados.

Los tres últimos capítulos de Violence and Society abordan aspectos importantes de lo que se conoce como 'violencia de las relaciones de género', aunque deberíamos encontrar otra forma mejor de denominación, en la medida que las mujeres, como los otros actores, pueden ser igualmente víctimas u observadoras de la violencia, pero también agredir o incitar a hacerlo. Es cierto que su aparición en las fuentes es sobre todo como víctimas, pocas veces se les reconoce como agresoras, y el testimonio de su observación está menos representado? No obstante, el artículo de Nancy Wicker («Selective female infanticide as partial explanation for the dearth of women in Viking Age Scandinavia», págs. 204-221) muestra lo oscurecida u oculta que puede estar esa visibilidad como víctimas, y propone una nueva lectura del material arqueológico, cuya importancia defiende, para abordar el difícil tema de la violencia en el ámbito doméstico (expresión que me parece más adecuada que la de violencia 'privada' utilizada por la autora), la infringida contra las niñas recién nacidas. La práctica de distintas formas de infanticidio selectivo es lo que, en su opinión, explicaría la escasez tanto de restos arqueológicos femeninos, como su menor presencia documental. Julie Coleman («Rape in Anglo-Saxon England», págs. 193-204), se centra igualmente en un tipo de violencia específica contra las mujeres: la violación, aunque este crimen producía un colectivo de víctimas además de la di-

7 Cuando, por ejemplo, contrapone asesinato 'privado' a 'político' (p. 132).

8 Un trabajo en este sentido es el objetivo de nuestro Proyecto de Investigación actual citado en $n .1$

9 El de la incitación parece ser el papel que culturalmente les corresponde. Páginas interesantes en este sentido las de MiLler, I. William en Bloodtaking, (págs. 212-214).

Hispania, LXI/2, núm. 208 (2001) 691-706 
rectamente afectadas, debido al agravio y ofensa familiar y ruptura de la paz regia que implicaba. Muestra esta autora las diversas actitudes y percepciones que tal violencia engendraba en relación al estatus familiar y social de la mujer agraviada en la Inglaterra anglosajona. El artículo de Ross Balzaretti («'These are things that men do, not women': the social regulation of female violence in Longobard Italy», págs. 175-192) se pregunta por las mujeres como sujetos de violencia y por las formas en que ésta se representa en las fuentes legales de la Italia lombarda. La negación y castigo legal de la violencia femenina que observa, considera es corolario al mismo tiempo tanto de su exclusión política y de lo apropiado de su domesticidad, como de la construcción de la masculinidad heroica dominante. Varios puntos suscitan estos capítulos que merecerían una discusión más detenida de la que es posible aquí, como los que se refieren a los elementos retóricos que se dan en la representación de la violencia sufrida por las mujeres, construida como criterio de desorden en relación a una retórica masculina de protección y patronazgo; o los referidos el carácter político o no de la violencia femenina; así como la reproducción de la desigualdad de género que resulta de la persistencia de una lectura positivista de las fuentes.

La preocupación por tratar los problemas y dificultades de nuestras fuentes para abordar el conocimiento de los procesos emocionales como vía para entender de forma más compleja la acción social parece haber inspirado los trabajos sobre de Anger's Past como la emoción que mejor expresa los sentimientos violentos en las sociedades medievales europeas. Es sobre las representaciones y percepciones de la ira, sobre las actitudes hacia la misma que versan los diez artículos de que consta el libro agrupados en cuatro apartados temáticos. En el primero, bajo el título de 'monjes y santos' se incluyen el artículo de Lester Little ('Anger in Monastic Curses' págs. 9-35) sobre la ira monástica y su expresión litúrgica, que ve como ritual que inhibe los estallidos emocionales violentos e influye en el proceso civilizador ${ }^{10}$; y el de Catherine Peyroux ('Gertrude's furor: Reading Anger in an Early Medieval Saint's Life', págs. 36-58) sobre la reacción airada de una niña, futura santa, ante una oferta matrimonial laica, estando ya prometida de Cristo; reacción que la autora explica de modo convincente, por referencia al contexto sociocultural y político de los actores y de la audiencia a la que la narración va dirigida, en relación a los modos de negociar las alianzas matrimoniales en esa sociedad.

10 En un artículo reciente Alain BOUREAu comenta la ineficacia de esa política litúrgica y la utilización de otra a partir del siglo XIII, aunque al igual que Little considera a los monasterios como 'fabrique de la civilité', -'Les moines anglais et la construction du politique (début du $13 \mathrm{e}$ siécle)' Annales, ESC, 3, 1999, pág. 640. 
El segundo apartado 'reyes y emperadores', trata de las iras regias e imperiales: Gerd Althoff ('Ira Regis: prolegomena to a History of Royal Anger', págs. 59-74) ofrece un adelanto de la historia sobre la ira regia que está escribiendo, ira que interpreta como uno de los instrumentos fundamentales de un sistema político de carácter personal, cuya legitimidad hubo de superar una larga tradición en contrario que se remonta a los carolingios; Geneviéve Bührer-Thierry ("«Just Anger» or "Vengeful Anger»? The Punishment of Blinding in the Early Medieval West', págs. 75-91) trata también del proceso por el que la ira pasa de ser condenada como abuso de poder, en una tradición que rastrea en la antigüedad clásica, a convertirse en manifestación de autoridad legitimada con visigodos y carolingios quienes transforman el castigo de cegar a los oponentes políticos de crueldad en un acto piadoso, debido a la influencia del clero de la corte en definir la función imperial de iluminar a la comunidad cristiana; en el último artículo de este apartado ('What Did Henry III of England Think in Bed and in French about Kingship and Anger', págs. 92-126) Paul Hyams elucubra, muy sofisticadamente por cierto, sobre los procesos de interiorización de ideas 'civilizadas' por un rey inglés del siglo XIII, a través de la iconografía edificante que adornaba la cámara real, que representaba la virtud de la clemencia triunfando sobre el pecado de la ira, en conjunción con otras influencias.

En un tercer apartado que trata de la ira de 'Señores y campesinos': Stephen White ('The Politics of Anger', págs.127-152) investiga la naturaleza y función política de la ira señorial y sus implicaciones, en un argumento que explícitamente cuestiona asunciones muy extendidas que la ven como signo de emotividad animal y, por tanto, de irracionalidad política, señalando el carácter estratégico que tiene en los procesos de disputas donde ocurre (del interés de su propia noción de 'política' nos ocuparemos más adelante); también Richard Barton (' 'Zealous Anger' and the Renegotiation of Aristocratic Relationships in Eleventh- and Twelfth-Century France', págs. 153-170) se ocupa del tema de la ira como componente esencial del poder señorial, signo y efecto de la autoridad legitimada sirve para reproducirla, a través de procesos de negociación, cuando se siente amenazada. En este sentido, pone de relieve la fuerza social positiva de las manifestaciones airadas como medio para la resolución 'pacífica' de disputas. Barton, sin embargo, parece reservar el sentimiento de ira solo a los aristócratas, o se limita a investigar las motivaciones emotivas de la conducta de este grupo. Pero podemos preguntarnos ies patrimonio de los nobles sentirse airados? ¿es la ira una emoción de los señores? ¿de la aristocracia? ¿qué pasa cuando los airados son campesinos?. Estas son las cuestiones sobre las que versa el artículo de Paul Freedman ('Peasant Anger in the Late Middle Ages', págs. 171-190) que, en cierta medida complementa el de Barton, al mostrar que lo que parece prerrogativa noble es la ira 'justa', pues la campesina en general se representa negativamente: ridícula o aterradora, cómica o asesina, dependiendo de si los protagonistas son individuos o colectivos, siempre irracional e instintiva. Las 'armas de los débiles' viene a decir Freedman, utilizando una bien conocida expresión de James Scott, no eran la valentía y confronta- 
ción abierta, sino la astucia y sagacidad, porque no se les reconoce honor ni dignidad que deban defender. La imagen construida y legada por las fuentes medievales respecto al campesinado les atribuye una violencia salvaje al tiempo que les niega esos vínculos emocionales de amor, honor e ira, propios de la caballería. Pero como para la aristocracia el discurso no es unívoco, también la ira campesina, como veremos, puede reconocerse como justa en algunos contextos, aquellos en los que sus opresores son representados negativamente como tiranos, de ahí que esa valoración positiva de la violencia campesina vaya ligada a una retórica restauradora de celebración del gobernante justo o de condena del injusto ${ }^{11}$.

Una cuarta y última parte, bajo el título de 'Celtas y Musulmanes', agrupa dos artículos de una forma, en mi opinión, un tanto forzada por cuanto pretende introducir criterios geográfico-religiosos, no suficientemente justificados, para tratar el tema. Uno, el de Wendy Davies ('Anger and the Celtic Saint', págs.191-202), podría haberse incluido en el primer apartado, pues se ocupa de la función destructiva de las maldiciones de los santos en las áreas célticas que ve asociadas no con la ira sino con la oración. En el material hagiográfico que maneja la ira se asocia más a reyes y aristócratas malos que a los santos, como pecado que debe ser castigado, aunque en el marco de una ética militar se construye como condición apropiada para la dominación de una aristocracia belicosa en las culturas campesinas altomedievales. Esta historiadora relaciona de forma expresa la función de la ira como defensa de honor y estatus a aparatos de estado muy limitados o poco formalizados. El otro artículo ('From Anger on Behalf of God to «Forbearance» in Islamic Medieval Literature', págs. 203232) podría haberse incluido en el segundo apartado que de forma más concreta trata del control institucional de la ira, pues su autor Zouhair Ghazzal, traza el proceso en la literatura islámica que va de la 'ira divina' a la 'tolerancia', ofreciendo datos de útil comparación. Cabe destacar el interés de su análisis de la noción de tolerancia, autocontrol (bilm en la literatura adab del siglo IX) y la dificultad de conceptualizarla, o como práctica recta determinada éticamente, o como simple 'virtú' maquiavélica por razones de estrategia política.

El material y argumentos que ofrecen estos artículos cobra un sentido mayor y más coherente aquí también por el trabajo de la editora Rosenwein, cuyas páginas introductorias (págs. 1-6), pero sobre todo las conclusivas ('Controlling Paradigms', págs. 233-247) no se limitan a presentar el contenido de los mismos sino que los enmarcan teóricamente destacando los puntos que se prestan a discusión y los desacuerdos entre los autores, participando también ella en los debates. Merece la pena que de su mano y a través de esta reseña participemos nosotros también. Pero antes, he de presentar el tercer libro.

11 Sobre el carácter de las representaciones del campesinado versa su nuevo libro Images of the Medieval Peasant, Stanford, California, 1999.

Hispania, LXI/2, núm. 208 (2001) 691-706 
Thomas Bisson, conocido y prestigioso historiador de la Cataluña medieval, al dejar hablar a las voces atormentadas que dan título a su libro, ofrece un buen contrapunto a la imagen 'salvaje' e 'irracional' de la ira campesina que Freedman ha mostrado ser construcción aristocrática. Los campesinos catalanes presentados por Bisson, son gentes justamente airadas ante las nuevas formas de dominación que hacia mediados del siglo XII se estaban generalizando en la zona, pues esa violencia, nos dice, la 'sintieron' como ruptura arbitraria y penosa de un antiguo orden. El tema de la violencia, del cambio de mentalidad respecto a su función social, que había sido central a la tesis de este autor sobre la revolución feudal ${ }^{12}$, esa quiebra y apropiación de la autoridad legítima por los poderes locales, es retomado en este libro de una forma, pienso, deliberadamente provocadora, pues de un modo más impresionista que entonces insiste en resaltar la violencia producida por la imposición de nuevos métodos de opresión por un señorío que estaba acabando con el 'orden público normativo' que había sobrevivido en Cataluña a la crisis del siglo XI, y estaba legitimando su misma arbitrariedad. Tan larga supervivencia, hace que el proceso de cambio parezca más lento de lo que Bisson proponía en su famosa tesis, y en cierta medida se aproxima a las propuestas por Freedman para los orígenes de la servidumbre en Cataluña ${ }^{13}$. Pero lo que está aquí en discusión no es el ritmo ni la cronología de tal cambio, aunque Bisson se afirme en los ya mantenidos (n. 12, pág.148), sino la realidad de esa violencia arbitraria fruto de un mal señorío auténtico leifmotiv del libro- que en opinión de su autor es negada, o al menos subvalorada, por aquellos que contextualizan dicha violencia en procesos conflictivos y/o consideran era el modo de resolución de disputas en sociedades sin estado. Para Bisson estos 'resolucionistas de disputas'14 como denomina a lo que considera una 'nueva escuela' de historiadores, dotarían de 'normalidad' la existencia de violencia en sociedades carentes de estado. La provocación viene de la lectura positivista, de simple 'sentido común compasivo' ('compassionate common sense') que él propone para captar la 'verdad histórica' ('bistorical truth') de sus fuentes ${ }^{15}$ (págs. 144-146), discusión que afecta al problema central de la función del historiador en la construcción de la realidad sobre la que escribe o intenta dar cuenta, a la lectura, por tanto, que hace de la información que maneja, problema éste al que se refieren todos y cada uno de los autores reseñados.

12 'The «Feudal Revolution»'. En el debate que este artículo suscitó, uno de los más interesantes y de mayor difusión de la revista, las discusiones sobre el papel de la violencia en la construcción de un nuevo orden político, mejor habría que decir de una nueva legitimidad, son de sumo interés. Ver referencias supra n.4. El debate es comentado por Halsall en su introducción (págs. 5-6).

13 La intervención de FrEEDMAN, en el debate en torno a la 'revolución feudal' puede verse en 'La servidumbre catalana y el problema de la revolución feudal', Hispania, 193 (1996) págs. 425-446.

14 Parecería ésta una forma de ridiculizar los argumentos del adversario, en vez de discutirlos razonadamente, con respeto y sin 'violencia'.

15 Estas expresiones en págs. 147 y VI respectivamente. Sobre las trampas del 'sentido común' advierte Bourdieu, P. en El sentido práctico, Madrid, 1990, especialmente en el cp. 2, pág. 100.

Hispania, LXI/2, núm. 208 (2001) 691-706 
Los 'memoriales de agravios', como denomina Bisson a los documentos que utiliza como información, le parecen retazos olvidados en los que están presentes las voces de los campesinos, protestando o quejándose de las violencias que les infringen nuevos señores, de la imposición de una nueva dominación, teniendo como referente un señorío condal o regio más benigno. Es esta invocación a un orden normativo, a una idea de justicia, que se dice quebrantada lo que le parece importante. La información que tal material ofrece parece deberse fundamentalmente a querellas dirigidas a la autoridad condal-real o a encuestas o pesquisas que ésta ordeno realizar en sus dominios ${ }^{16}$. Sin embargo Bisson, atento sólo al 'dolor' de los que se quejan, no presta atención al marco de competición por el poder que indica ese tipo de fuente judicial, aún entendida en sentido amplio, ni a los pocos casos en los que la violencia, como él mismo señala, parece resultado de guerras entre señores (págs. 26 y 96). La pregunta subyacente y a veces explícita (pág.144) es la de si hay que entender esas referencias a la violencia como una estrategia retórica en un contexto conflictivo o como reflejo de una realidad. Esta cuestión así formulada es equívoca, pues debería aceptarse que las estrategias de cualquier signo forman parte de la realidad que analizamos, de los procesos de los que forman parte, en los cuales cumplen una o más funciones. Preguntarse por la función que cumple la representación de una situación, en este caso la de la violencia denunciada, no implica negar ésta, pero si tratar de entenderla de forma más compleja, sin dicotomías moralistas que tergiversan los procesos sociales que analizamos. Así, comprobar el marco conflictivo en el que se escribieron los documentos utilizados por Bisson, tendría que servir no solo para hacerse eco de la voz atormentada de las víctimas, sino tal vez para entender también como esas quejas pudieron servir de instrumento para construir o recuperar un poder frente a los denunciados como agresores; plantear que las víctimas también pudieron serlo como resultado de esas luchas y no como fruto simplemente de la arbitrariedad de unos aristócratas. Esto no supone disminuir el dolor ni la violencia que sufrieron, tal vez simplemente entender -como muchos de los artículos aquí reseñados muestran - que los procesos de lucha por imponer un nuevo poder, por restaurar o mantener uno anterior son en sí mismos violentos. Pero Bisson, pese a reconocer el carácter parcial y problemático de sus evidencias, tiene interés en mostrar que la violencia de la que se quejan sus ${ }^{17}$ campesinos, se derivaba de la coerción señorial y no era fruto de guerras o venganzas personales en una sociedad sin estado.

$16 \mathrm{El}$ análisis de lo dieciséis documentos utilizados, que Bisson presenta en el primer capítulo del libro (págs. 1-27), es realmente minucioso. Sobre la diversidad de estos memoriales y el carácter que cabe atribuirles reflexiona en el tercer capítulo (págs. 72-80).

17 Utilizo este posesivo, para indicar que es su interpretación, pues algunos de los datos que aduce plantean dudas acerca del carácter campesino de los protagonistas, como en el caso en el que se les presenta habiendo sido desposeídos de caballos (págs. 49 y 131). 
La discusión, por tanto, afecta también a la relación que se establece entre formas de violencia y la existencia, o no de estructuras políticas organizadas, cuestión a la que me refería en páginas más arriba como merecedora de atención, pues articula de forma explícita gran parte de los argumentos o subyace de modo implícito en los trabajos reunidos en estos libros. Constituye el grueso de los comentarios introductorios de Halsall, es crucial en la argumentación de Bisson e inseparable igualmente en las tesis del proceso civilizador que discute Rosenwein. La opinión más generalizada parece considerar que determinadas formas de violencia, de competición política, sólo se habrían dado en sociedades donde el poder no estaba políticamente institucionalizado, o era muy débil, es decir, se asocian a carencia de 'estado' y de 'política' por implicación. Sin embargo, detrás de lo que parece una común asunción hay variadas concepciones, entre otras cosas porque los términos actuales utilizados para referirse tanto a la violencia como al poder no responden a un mismo contenido. Es ilustrativo en este sentido el debate suscitado en torno a la denominación y significado que cabe dar a conflictos que en las fuentes aparecen como inimicitia, guerra, bellum, venganza, querimonia, contienda, intentio...por referirme a los que son comunes a las fuentes medievales europeas.

La función de estructurador social que algunos antropólogos han atribuido a estos conflictos en las sociedades por ellos estudiadas, sin una organización política formalizada —o no tan formalizada como nuestro referente cultural-, junto a una noción actual muy estricta de un tipo de violencia como mecanismo utilizado en defensa propia, entendido como intercambios sin fin de violencias vindicatorias, - - piénsese en el término inglés feud, o el nuestro de venganza de sangre-, que no responde a la información medieval que se conserva de modo predominante para estos conflictos, ha impulsado en gran medida los estudios que comentamos. El hecho de encontrar evidencias que muestran que esos conflictos podían finalizar por compensación en vez de por sangre, que la violencia podía ser simple amenaza estratégica, que era frecuente y estaba regulada legalmente, que había intervención judicial en su resolución, en definitiva, que podían terminarse, ha llevado a tratar de distinguir unas de otras prácticas, y a buscarle un nombre más apropiado para denominarlas. Así Halsall, en vez de feud propone el de customary vengeance para la lucha por el poder local en las sociedades altomedievales, en un epígrafe que gráficamente titula feud, vengeance and 'civil' war (las comillas son del autor, págs. 19-29). En vez de aceptar, como han hecho otros autores ${ }^{18}$, la variedad de denominaciones de las fuentes para esas luchas, y rechazar la acepción limitada del término actual, se esfuerza por ponerle un nombre que lo diferencie de éste y se obliga a calificar al feud como verdadero cuando responde al contenido que le atribuyen los diccionarios,

18 WHITE, 'Feuding'; MILLER, Bloodfeud; ALFONSO, I.: 'Litigios por la tierra y «malfetrías» entre la nobleza medieval castellano-leonesa', en Hispania, 197 (1997), págs. 917-955. 
vinculándolo a sociedades sin estado, o a momentos de debilidad política ${ }^{19}$. Sus consideraciones sobre la noción de guerra aunque interesantes son también problemáticas y discutibles, en la medida que parece reservar para ésta un contenido político que no da a las venganzas. Ilustran bien acerca de las dificultades para trazar una tipología de violencias, o establecer unos criterios para denominarlas. Tiene razón, por tanto, al decir que las valoraciones sobre el período estudiado vienen marcadas por la naturaleza que se atribuya a esos conflictos, en argumentos que, en mi opinión, suelen devenir circulares, pues el debate afecta también como decíamos al contenido que el historiador de a la noción de 'estado', cuando ésta es la de un tipo ideal weberiano, la violencia y acción política nobiliaria es vista siempre como particularista. Más acertado y útil parece insistir en investigar el grado y naturaleza del control del aparato político sobre esos conflictos en ámbitos locales, como propone el mismo Halsall, profundizar en los cambios en la expresión de la violencia y su control, de su representación y legitimación, en relación con los cambios en las estructuras de poder, pero en una línea que no oponga desarrollo estatal y desaparición de 'venganzas', que no vea justicia y venganza como opuestos lógicos ${ }^{20}$.

Estrechamente relacionado con estos problemas se sitúa el debate sobre el proceso civilizador, igualmente ligado a una noción de estado y a un desarrollo evolutivo lineal hacia estadios más civilizados y, por ello, menos violentos, a veces también de mayor desarrollo cognitivo ${ }^{21}$, en todo caso, de mayor inhibición de las emociones. Como dice Rosenwein el criterio diferenciador del material de su libro estriba en asumir, de forma más o menos explícita, ese paradigma del proceso histórico civilizador, entendido sobre todo como el del con-

19 El problema de nuevo es el término a utilizar, que parece el motivo que ha obligado a Halsall a distinguir feuds, en ausencia de estado, de customary vengeances, cuando las controla, distinción que en cierta medida permite la oposición que se pretende negar. Un desarrollo más extenso a sus argumentos, pero no más clarificador, lo da en su artículo 'Reflections on Early Medieval Violence: The example of the "Blood Feud»' en Memoria y Civilización. Anuario de Historia (Universidad de Navarra), 2, 1999, págs. 7-29.

20 Robert Barlett cuestiona el axioma, y sus implicaciones, de que 'la fortaleza de la enemistad legal y la del estado varíen inversamente', "Mortal enmities' págs 13; Paul Hyams al señalar que esas formas de lucha debían ser vistas como parte integral de la cultura de la nobleza medieval en todas partes, incluso en áreas de bien definida autoridad central, pretende 'matizar los contrastes convencionales entre regímenes precozmente centralizados y otros de la Europa Continental', 'Feud...' p. 21. Para una critica de la oposición entre justicia y venganza, ver ALFONSO, Isabel: 'Justicia y venganza en el Cantar del Cid' (en prensa). De gran interés para este debate, algunos de los planteamientos de DEAN, Trevor: 'Marriage and mutilation: vendetta in late medieval Italy' en Past and Present, 157 (1997), págs. 3-36, y SMAIL, Daniel L. 'Common violence: vengeance and inquisition in fourteenth-century Marseille' en Past and Present, 151, (1996), págs. 28-59.

21 Muy significativos en este sentido los argumentos de Little que asume la muy difundida tesis de RADDING, M.: sobre los diferentes niveles de desarrollo cognitivo que irían de menor a mayor racionalidad $A$ World Made by Men: Cognition and Society, 400-1200, Chapel Hill, 1985.

Hispania, LXI/2, núm. 208 (2001) 691-706 
trol emocional, o en proponer modelos de interpretación alternativos. Ella misma parece alinearse en esta propuesta que entiende el cambio histórico no como el de la restricción civilizadora de emociones y violencia descontroladas, sino como la transformación de un conjunto de convenciones y represiones en otro. De este modo, considerando un error buscar claros 'turning points' en el desarrollo civilizador, da un sentido diferente a los artículos que asumiendo las tesis de Elías, simplemente las habían adelantado o situado en otros espacios de socialización, como el de Little respecto a la liturgia monástica o el de Hyams a la judicial. Es más, nos dice, el 'violento' siglo XI, llega a ser tan civilizado como el XVI, si por civilizado entendemos tener y seguir reglas y códigos sociales que limitan la conducta (pág. 233)

Es interesante notar que la noción de política y, por tanto, de acción política o politización que se discute en este contexto no va, o no solo, como ocurría en los otros dos libros, referida a unas estructuras de gobierno formalizadas, a un determinado desarrollo administrativo, sino al grado de desarrollo que se reconoce a las estructuras emocionales. Así, por ejemplo, se plantea si las manifestaciones airadas de los reyes son expresiones de sentimientos impulsivos y espontáneos, o recursos políticos a su disposición. Cabría preguntarse a partir de algunos textos si se civilizaron los reyes ingleses reprimiendo su ira y practicando la tolerancia, por influencia clerical, como pretende $\mathrm{Hyams}^{22}$, o si utilizaron o reprimieron la manifestación de esta emoción con objetivos políticos, como interpreta White. Las implicaciones de una u otra respuesta son muy diferentes, pues mientras el primero lo entiende siguiendo la vía civilizadora, el segundo niega la existencia de tal vía, pero sobre todo propone entender su manifestación como una práctica política de mayor implicación que una experiencia individual, en el mismo sentido que señala Ghazzal para un contexto cultural diferente. White señala muy bien las graves implicaciones de asociar ira a emocionalismo, violencia a irracionalidad política. Su respuesta foucaultiana, que asumo, es que las formas de ira regia o señorial (tanto laicas como eclesiásticas), abiertas o simbólicas, eran elementos de una 'tecnología del poder' y/o remitían a una determinada ética. Rosenwein previene contra grandes generalizaciones acerca de las instituciones políticas disponibles a los gobernantes medievales y sugiere atender a diferentes momentos en los que la ira puede ser justificada o condenada.

En definitiva, estas consideraciones nos llevan al último punto, el de la construcción narrativa como discurso de legitimación o condena de unas u otras violencias, el del control y criterios para hacerlo, problemas con los que iniciaba estas notas, en las que he privilegiado referirme a las formas de violen-

${ }^{22}$ La interpretación de este autor, sin duda, es más compleja pues si por un lado parece entender el aprendizaje educativo como un proceso de interiorización del control emoćional, por otro apunta a la justicia regia y su derecho como los instrumentos que anulan la ira señorial. 
cia que resultan de la competición y lucha política en sentido amplio, y que están presentes en los trabajos reseñados. De estos trabajos se desprende, que tal como afirma Miller, la violencia es una noción sin contenido fijo y preciso, una categoría analítica problemática en sí misma, cuya percepción, cualificación y representación como proceso social que es, ha de entenderse condicionada cultural, histórica y normativamente ${ }^{23}$.

Se ha visto que el control de la legitimidad pasa en gran medida por los nombres que se da a la violencia, por la definición que se imponga de los conflictos, pero que ésta no es simplemente una cuestión de vocabulario, porque el hecho de cualificar un acto o proceso como violento, no puede entenderse como un aspecto separado de las relaciones de poder, del proceso de dominación política que lo produce. Nombrar, calificar, legitimar y condenar la violencia son en sí mismas formas de lucha política también. En este sentido, la falta de acuerdo entre los historiadores en cómo calificar, nombrar, definir, los tipos de violencia que observan en la competición política, la extensión con que se discute, es indicativa no tanto de la ambigüedad y flexibilidad de estas denominaciones, como de que el propio hecho de nombrar y las estrategias discursivas son elementos de la misma lucha que su legitimación tiene que ver en gran medida con la denominación que prevalezca del conflicto. Por ello los términos que nuestras fuentes nos ofrecen hemos de considerarlos en gran medida resultante de esas luchas, frutos de un poder o autoridad reconocidos.

Es sabido el carácter legitimador que tiene representar una acción violenta como guiada por intereses generales (la dimensión será la del grupo al que se dirija e interese), con frecuencia caracterizados como públicos. Recurso retórico fundamental, es esta construcción de una noción de 'público' como referente por excelencia de toda legitimidad la que me parece necesita mayor investigación. Pero no sólo eso, se trataría de conocer, de preguntarse por la construcción histórica de otros conceptos que legitiman el poder y la violencia que éste conlleva, de averiguar cómo contribuyen a la naturalización del orden establecido y buscar alternativas que la han cuestionado y se le han opuesto. Es en este sentido en el que hay que aceptar que la deconstrucción de estos conceptos, de las convenciones que encierran, en sí misma tiene poder de cambio ${ }^{24}$. La variada contribución en esta línea de los libros comentados merece ser destacada.

23 Miller, Humilliation, todo el cap. 2 contiene reflexiones de gran interés para hacer consciente nuestra propia percepción de la violencia.

24 Sobre deconstrucción como proyecto ético ver CRICHLEY, S.: The Ethics of Deconstruction: Derrida and Levinas, Oxford, 1992.

Hispania, LXI/2, núm. 208 (2001) 691-706 